\title{
Milk-borne infection
}

\author{
J. C. M. SHARP
}

Communicable Diseases (Scotland) Unit, Ruchill Hospital, Glasgow G20 9NB

\section{Introduction}

Milk-borne infection was prevalent in Scotland throughout the 1970s and early 1980s. During the 13-year period 1970-82, 50 outbreaks of milk-borne salmonellosis affecting more than 3500 persons, of whom 12 died, were recorded at the Communicable Diseases (Scotland) Unit (Sharp et al., 1980; Reilly et al., 1983); some of these involved hundreds of consumers of untreated milk (Maclachlan, 1974; Small and Sharp, 1979). Several outbreaks of other milk-borne infections, particularly campylobacter enteritis, were also reported (Porter and Reid, 1980).

\section{Legislation in Scotland}

The economic losses to the health services, to society and to the dairy industry were considerable. A costing study of one outbreak of salmonellosis affecting more than 650 persons, of whom two died, in the town of Keith in north-east Scotland in 1981 estimated a total minimum cost of $£ 236000$ and a maximum of $£ 3222000$ with a mid-range average cost per patient of $£ 2637$. The study also demonstrated the cost-effectiveness of heat-treating all cows' milk; namely, that the costs of heat-treatment would be less than those attributable to the considerable morbidity, and occasional mortality, associated with milk-borne infection (Cohen et al., 1983). Consequently, and complemented by the epidemiological and microbiological data available, legislation was implemented in Aug. 1983 prohibiting the retail sale of untreated cows' milk in Scotland. Thereafter, the large general-community outbreaks of milk-borne salmonellosis and campylobacter enteritis previously experienced were successfully controlled (Sharp et al., 1985). Exemptions to the legislation, permitting the sale of raw milk, were given initially, in 1983 , to 11 small producer-retailer dairy-farms on several Scottish, outer islands (Shetland, Islay, Raasay, Benbe-

Received 24 Jan. 1989; accepted 28 Feb. 1989. cula, Mull and Colonsay) where pasteurisation facilities were not readily available. By Jan. 1989, only one small dairy farm on the island of Colonsay continued to receive exemption, subject to further annual review (Mr G. M. Paterson, personal communication). Untreated goats' and sheep milk were also exempt because dairy legislation throughout the UK relates to cows' milk only.

The success of the legislative control measure, however, highlighted the prevalence of milk-borne infection in dairy-farming communities where farmworkers and their families continued to receive untreated milk as a wage-benefit, a practice not prohibited by the 1983 legislation because retail sale was not involved; between Jan. 1983 and Dec. 1985,14 farm-community outbreaks of salmonellosis were recorded (Forbes et al., 1986). In one other incident, employees at a cheese-making factory, who had been drinking milk prior to its being heat-treated, were infected by both Salmonella and Campylobacter spp. In Sep. 1986, further control measures were introduced with the Scottish Agricultural Wages Board's decision that, thereafter, only heat-treated milk, and not untreated milk as previously, could be given to farmworkers as a wage-benefit. In 1986, two small outbreaks of salmonellosis in farming communities were reported; since then, further outbreaks of milk-borne infection of any significance have not been recorded.

Outwith farming communities, three milk-borne campylobacter outbreaks were recorded in Scotland during 1983-85; one occurred before Aug. 1983, one affected a family who had consumed raw milk whilst on holiday in England, and another involved campers who had illegally been sold raw milk from a dairy farm, when their usual heat-treated supply ran out (Anderson et al., 1985). More recently, in June 1987, a group of cub-scouts, who consumed raw milk gifted by a local farmer on whose land they were camping, developed campylobacter enteritis (table).

The consumption of untreated cows' milk is not 
Table. Outbreaks of milk-borne infection reported in Scotland, 1980-88

\begin{tabular}{lccc}
\hline & & \multicolumn{2}{c}{ Number of } \\
\cline { 3 - 4 } \multicolumn{1}{c}{ Infection } & Period & Outbreaks & Persons affected \\
\hline Salmonellosis & $1980-82$ & 21 & $1146(55)^{*}$ \\
& $1983-85 \dagger$ & 15 & $101(7)$ \\
& $1986-88_{\ddagger}^{\dagger}$ & 5 & $21(4)$ \\
Campylobacter & & & \\
enteritis & $1980-82$ & 6 & $278(46)$ \\
& $1983-85$ & 3 & $25(8)$ \\
& $1986-88$ & 4 & $24(6)$ \\
\hline
\end{tabular}

* In parentheses, the average number of persons affected per outbreak.

† The Milk (Special Designations) (Scotland) order 1980 implemented on 1 Aug. 1983.

$\ddagger$ The Agricultural Wages order number 34 introduced on 1 Sep. 1986.

totally prohibited in Scotland. It is not illegal for dairy farmers, their families and friends to drink raw milk obtained from their own herds, where no retail sale or wage-benefit contract is involved. Minor episodes of milk-borne salmonellosis and campylobacter enteritis continue to be reported from time to time among these groups. In addition, in south-west Scotland over a 3-month period in 1987 , for example, several incidents of salmonellosis, campylobacteriosis, with or without cryptosporidiosis, were investigated in farming families, all of whom regularly drink raw milk; whether or not infection was acquired from contaminated milk could not be ascertained (Dr L. Kilpatrick, personal communication). In the summer of 1988 Campylobacter spp. were isolated from a child who became ill on her return from a self-catering holiday on the island of Colonsay, during which she drank unpasteurised milk.

\section{Elsewhere in the UK}

In England and Wales outbreaks of milk-borne salmonellosis, campylobacter enteritis, and infections with Streptococcus zooepidemicus and Corynebacterium ulcerans were also reported during the 1970s and 1980s (Robinson and Jones, 1981; Galbraith et al., 1982; Barrett, 1986; Edwards et al., 1988). Legislation was introduced in Nov. 1985 prohibiting the sale of untreated cows' milk through shops, supermarkets, canteens and other retail outlets but, unlike the legislation in Scotland, continued to permit sales of raw milk direct from producer-retailer dairies or via local farm deliveries in rural districts in many parts of the country and, in particular, in Lancashire and West Yorkshire. Various pressure groups further persuaded the government to relax some of the requirements of the legislation, permitting the continued provision of untreated milk as part of a catering sale for tourists and other farm visitors. More recently, however, in Feb. 1989, the Minister for Agriculture, Fisheries and Food declared the intention to ban the sale of all untreated cows' milk in England and Wales in the near future.

The increase in milk-borne infection observed in the UK in recent decades can be explained only partly by improved surveillance. Of probable greater significance are the changes which have been taking place in the dairy industry as a consequence of advancing technology and economic pressures. The average number of cows per herd in Scotland doubled from 45 to 90 between 1965 and 1984 and from 26 to 67 in England and Wales (UK Dairy Facts and Figures, 1965 and 1984), whilst the average number of milking cows per dairyman also doubled in parallel, thus minimising the time available for attention to individual animal hygiene. The potential exposure of milk to contamination during production almost certainly increased as a consequence of these changes.

\section{The situation in other countries}

Elsewhere in Europe, untreated milk can still be obtained in rural districts of most countries. Only in Denmark, Norway, Finland, Iceland and Yugoslavia is there a total prohibition on the sale of all untreated dairy produce as is cows' milk in Finland and Scotland. While relatively few milk-borne outbreaks are reported, the dairy industry in Europe is notably less intensive than in the UK. Raw milk can also be sold under certain licensing conditions in 20 states of the USA and in seven of the 10 Canadian provinces and territories, although untreated dairy produce is generally not widely available. Milk-borne salmonellosis and campylobacter enteritis are reported from time to time in North America, although more unusual was an outbreak of chronic diarrhoea of undetermined aetiology associated with raw-milk consumption in the town of Brainerd, Minnesota (Osterholm et al., 1986). In Alberta, the only province in Canada without relevant heat-treatment legislation, onethird of all cases of campylobacter infection reported during 1985 and 1986 were attributed to 
drinking unpasteurised milk (Alberta Medical Association, 1988).

\section{Other dairy industries and products}

The goat and sheep dairy industries in Britain have expanded in recent years and, whilst heattreated produce is available, a considerable market for untreated milk and cheese has developed. Outbreaks of brucellosis, campylobacteriosis, salmonellosis, listeriosis, toxoplasmosis, staphylococcal enterotoxin "food-poisoning" and C. ulcerans "sore throat" associated with untreated goats' milk have been recorded in Canada, the USA and in the UK. In one episode in Scotland, two persons who had taken goats' milk with their coffee during a farm visit developed staphylococcal "food-poisoning" (Report, 1985). A survey of goats' milk in England indicated that any contamination problems present were related to poor hygiene practices during production rather than by transmission of organisms from the animal itself (Roberts, 1985). Cheese made from untreated sheep's milk caused two outbreaks of staphylococcal "food-poisoning" in Scotland over the festive season of 1984-85; examination of cheeses from the farm of origin revealed heavy contamination by staphylococcal organisms and enterotoxin; numerous coliforms were also present (Dr F. J. Bone, personal communication).

Cream has featured only occasionally as a vehicle of food-borne infection. Commercially produced cream is almost always heat-treated and has a very good record. Legislation was implemented throughout the UK in 1983 relating to the heat-treatment of cream (compulsory in Scotland only) and of milkbased drinks, although these did little more than consolidate what had been, for commercial reasons, almost universal practice for many years.

\section{Aspects of heat-treatment failures}

Heat-treatment, however, is no excuse for producing dirty milk and must be regarded as complementary to other control measures such as good hygiene and correct operational practices throughout, from producer to consumer. Potential production problems during the pasteurisation process undoubtedly exist-failure to achieve effective temperatures or times can occur (Adams et al., 1984); incorrect temperatures may also be inadvertently applied in plants alternating between heat-treatment for liquid-milk sales and the lower temperatures frequently used in cheese-making; temporary plant breakdown can occur from electrical failure, such as during severe-winter weather conditions (Porter and Reid, 1980); whilst contamination after heat-treatment may arise from faulty equipment or human error or both.

In addition, spore-bearing organisms such as Bacillus cereus, a common dairy contaminant, will readily survive pasteurisation, although only occasionally have they featured as a cause of milk-borne disease. Preformed heat-stable staphylococcal enterotoxin is not destroyed by pasteurisation. After an outbreak of listeriosis in Massachussetts, USA, it was suggested that a large inoculum of microorganisms, particularly those such as Listeria spp. with the ability to exist intracellularly, may survive heat-treatment (Fleming et al., 1985). Although the results of subsequent experimental work in various countries led to differences in the respective conclusions, the WHO Working Group on "Foodborne Listeriosis" which met in Geneva in Feb. 1988 , concluded that pasteurisation is a safe process reducing the number of $L$. monocytogenes to levels that do not pose an appreciable risk to human health and that further research on the pasteurisation of milk is not necessary (WHO, 1988).

During the 6-year period (1980-85) several outbreaks of milk-borne infection (salmonellosis, campylobacteriosis, yersiniosis, listeriosis, staphylococcal "food-poisoning") associated with contaminated heat-treated milk supplies were reported from North America and several European countries (Sharp, 1987). The most extensive of these occurred in April 1985 in Illinois and adjacent states of the USA, affecting more than 16000 persons (Ryan et al., 1987). During the latter months of 1985 and early 1986, more than 60 cases of infection by Salmonella ealing were identified in different parts of the UK, mainly affecting infants who had been fed with a particular brand of powdered milk (Rowe et al., 1987). Outbreaks of yersiniosis (Barrett, 1986) and salmonellosis (Rampling et al., 1987) in England have also been associated with pasteurised milk supplies.

Yersinia spp. were isolated from pasteurised milk supplies which had satisfactorily passed the phosphatase test in a survey in south-west Scotland (Morgan-Jones et al., 1986). A further reminder that there can be no room for any complacency in Scotland occurred in 1986 when two separate milk supplies to Glasgow hospitals were found to be heavily contaminated with coliform organisms with or without toxin non-producing staphylococci, viz., Staphylococcus hominis. (Dr J. Gordon, personal communication). Investigation at the respective processing dairies revealed several malpractices requiring immediate attention (Mr G. M. Paterson, personal communication). 


\section{Conclusions}

The legislative control measures introduced in 1983 and 1986, respectively, have effectively minimised the incidence of milk-borne infection in Scotland, in contrast to the experience of previous years and to that elsewhere.

\section{REFERENCES}

Adams D et al. 1984Salmonellosis from inadequately pasteurised milk-Kentucky. Morbidity and Mortality Weekly Report 33/36: 505-506.

Alberta Medical Assocation 1988 AMA members sour over raw milk. Canadian Medical Association Journal 139: 898.

Anderson S, Haines D, Jones I G 1985 An outbreak of campylobacteriosis possibly caused by unpasteurised milk. Communicable Diseases Scotland Weekly Report 19/47: 5.

Barrett N J 1986 Communicable disease associated with milk and diary-products in England and Wales-1983-1984. Journal of Infection 12: 265-272.

Cohen D R, Porter I A, Reid T M S, Sharp J C M, Forbes G I, Paterson G M 1983 A cost-benefit study of milk-borne salmonellosis. Journal of Hygiene 91 : 17-23.

Edwards A T, Roulson M, Ironside M J 1988 A milk-borne outbreak of serious infection due to Streptococcus zooepidemicus (Lancefield group C). Epidemiology and Infection $101: 43-51$.

Fleming D W et al. 1985 Pasteurized milk as a vehicle of infection in an outbreak of listeriosis. New England Journal of Medicine 312: 404-407.

Forbes G I, Sharp J C M, Collier P W, Reilly W J, Paterson G M 1986 Milk-borne salmonellosis affecting farming communities in Scotland. Communicable Diseases Scotland Weekly Report 20/26: 7-9.

Galbraith N S, Forbes P, Clifford C 1982 Communicable disease associated with milk and dairy products in England and Wales, 1951-80. British Medical Journal 284: 1761-1765.

Humphrey T J, Meade G C, Rowe B 1988 Poultry meat as a source of human salmonellosis in England and Wales. Epidemiological overview. Epidemiology and Infection 100: 175-184.

Lancet (Leading article) 1988 Salmonella enteritidis phage type 4: chicken and egg. Lancet 2: 720-722.

Maclachlan J 1974 Salmonellosis in Midlothian and Peeblesshire. Public Health 88: 79-87.

Morgan-Jones S C, Bone F J, Dale B A S, Hardie R 1986 Yersinia species in pasteurised milk. Communicable Diseases Scotland Weekly Report 20/39: 7-8.

Osterholm M T et al. 1986 An outbreak of a newly recognized
Food-borne salmonellosis, however, along with campylobacter enteritis, shows little sign of decreasing in incidence in the UK with poultry meat (Humphrey et al., 1988; Reilly et al., 1988) and more recently, egg-borne infection (Lancet, 1988; Sharp, 1988), having become increasingly prominent in the 1980s.

chronic diarrhea syndrome associated with raw milk consumption. Journal of the American Medical Association 256: 484-490.

Porter I A, Reid T M S 1980 A milk-borne outbreak of campylobacter infection. Journal of Hygiene 84: 415-419.

Rampling A, Taylor C E D, Warren R E 1987 Safety of pasteurised milk. Lancet 2: 1209.

Reilly W J, Sharp J C M, Forbes G I, Paterson G M 1983 Milkborne salmonellosis in Scotland 1980 to 1982. Veterinary Record 112: 578-580.

Reilly W J, Forbes G I, Sharp J C M, Oboegbulem S I, Collier P W, Patęrson G M 1988 Poultry-borne salmonellosis in Scotland Epidemiology and Infection 101 : 115-122.

Report 1985 The compleat investigator-or is Koch still postulating? Communicable Diseases Scotland Weekly Report 19/31: ix.

Roberts D 1985 Microbiological aspects of goat's milk. A Public Health Laboratory Service survey. Journal of Hygiene 94: 31-44.

Robinson D A, Jones D M 1981 Milk-borne campylobacter infection. British Medical Journal 282: 1374-1376.

Rowe B et al. 1987 Salmonella ealing infections associated with consumption of infant dried milk. Lancet 2: 900-903.

Ryan C A et al. 1987 Massive outbreak of antimicrobialresistant salmonellosis traced to pasteurized milk Journal of the American Medical Association 258: 3269-3274.

Sharp J C M, Paterson G M, Forbes G I 1980 Milk-borne salmonellosis in Scotland. Journal of Infection 2: 333-340.

Sharp J C M, Paterson G M, Barrett N J 1985 Pasteurisation and the control of milkborne infection in Britain. British Medical Journal 291 : 463-464.

Sharp J C M 1987 Infections associated with milk and dairy products in Europe and North America, 1980-85. Bulletin of the World Health Organization 65: 397-406.

Sharp J C M 1988 Salmonellosis and eggs. British Medical Journal 297: 1557-1558.

Small R G, Sharp J C M 1979 A milk-borne outbreak due to Salmonella dublin. Journal of Hygiene 82: 95-100.

UK Dairy Facts and Figures 1965 and 1984 The Federation of UK Milk Marketing Boards.

WHO Working Group 1988 Foodborne listeriosis. Bulletin of the World Health Organization 66: 421-428. 